\title{
Asia's Indigenous Horticultural Crops: An Introduction
}

\author{
Beiquan Mou' ${ }^{1,3}$ \\ U.S. Dept. of Agriculture, Agricultural Research Service, 1636 East Alisal Street, Salinas, CA 93905 \\ Guangyao Wang ${ }^{2}$ \\ Maricopa Agricultural Center, University of Arizona, 37860 W. Smith-Enke Road, Maricopa, AZ 85138-3010
}

Asia covers a wide range of geographic areas and climates and is one of the most horticulturally dynamic regions in the world. There is a great biological diversity of plants in this region. It also has a long history of agriculture and many horticultural crops have evolved there. As a matter of fact, more than half of the food crops in the world have originated in Asia. Besides agronomic crops like rice, wheat, barley, oat, soybean, and alfalfa, horticultural crops from Asia include fruits (apple, apricot, banana, cherry, grape, kiwifruit, lemon, lime, lychee, mandarin, mango, orange, pear, persimmon, and quince), nuts (almond, coconut, and pistachio), vegetables (carrot, Chinese cabbage, chives, cucumber, daikon, eggplant, garlic, lettuce, onion, pak-choi, spinach, and turnip), spice (black pepper, cinnamon, and ginger), medicine (ginseng), and ornamentals (Asian crabapple, camellia, chrysanthemum, Japanese cherry, maple, and plum, and Korean rhododendron, just to mention a few common plants). Although these crops are well recognized in the West, many other native crops of Asia remain unknown in the United States. To introduce these crops to American researchers and consumers, the Working Group of Asian Horticulture in the American Society for Horticultural Sciences organized a workshop, “Asia's Indigenous Horticultural Crops," at the 2009 annual conference of the society in St. Louis, MO. The papers from pages $819-838$ in this issue are adapted from presentations at the workshop.

Asia has a fast growth rate, and more than half of the world's population resides there. The high population density means that there is not a lot of land to raise or feed farm animals for human consumption. Asian people have relied on plants for food, feed, fabric, fuel, and ornament for centuries. Indigenous horticultural crops play an especially important role in human nutrition. Most Asians do not have the economic ability

\footnotetext{
Received for publication 13 Dec. 2011. Accepted for publication 10 Jan. 2012.

This paper was part of the workshop "Asia's Indigenous Horticultural Crops" held 26 July 2009 at the ASHS Conference, St. Louis, MO, and sponsored by the Working Group of Asian Horticulture (WGAH).

USDA is an equal opportunity provider and employer.

${ }^{1}$ Research Geneticist.

${ }^{2}$ Cropping Systems Specialist and Assistant Professor.

${ }^{3}$ To whom reprint requests should be addressed; e-mail beiquan.mou@ars.usda.gov.
}

or habit to take vitamin/mineral supplements. Many Asian diets are high in native vegetables to meet people's nutritional needs. The plant-based food has contributed to the generally slim bodies of Asian people. However, with the introduction of high-fat, high-sugar, and high-calorie fast food in recent years, obesity and obesity-related diseases such as heart diseases and diabetes have been increasing at an alarming rate. This demonstrates the importance and advantage of traditional diets with high proportions of native vegetables and fruits for human health.

Just like herbal medicine, native horticultural crops have been used to cure diseases by Asian people for a long time. Long before the appearance of "functional foods" in the West, native fruits, nuts, vegetables, and even some ornamentals were used in diets to cure illness, especially chronic diseases. They are also combined in daily diets to increase body strength, stimulate or strengthen the immune system, prevent diseases, and increase lifespan. In Asia, it is very common for older or middle-aged people to consume native plants for medicinal uses. Food remedies are especially popular in rural areas. The modern pharmaceutical industry now extracts, concentrates, or synthesizes the a.i. from plant materials to increase efficacy and convenience and develop new drugs.

Native horticultural crops are very important in the regional economy. Most farmers in Asia are small-scale growers and hope to maximize their return on limited acreage. Horticultural crops usually have much higher value than agronomic crops and can increase growers' incomes. The planting, cultivation, irrigation, fertilization, disease/insect/weed management, harvesting, and post-harvest storage and processing of horticultural crops are labor-intensive, which provides many employment opportunities. The transportation, wholesale, and retail of the crop products as well as the seed, fertilizer, pesticide, machinery, and supply companies all add to the local economy. The Asian population growth coupled with rising personal income through economic development has rapidly expanded the needs for food and other resources. After the realization of many adverse effects of modern fast food, traditional diets and native horticultural crops have been "rediscovered" and become popular again. The increasing demands have fueled the growth of the production of these crops, contributing substantially to the income and well-being of millions of people in the agricultural sector and consumers.

The indigenous crops also bring diversity to agriculture to ensure increased and sustainable food production. Crop diversity is an urgent issue in horticulture today. Like in the West, modern monoculture has dominated in Asia resulting in narrow genetic bases of crops. Thus, growers face increased risks both biologically and economically, because the erosion of variability makes crops vulnerable to attacks of diseases and insects as well as climate changes and other abiotic/biotic stresses. The availability of a large number of native crops makes it easy for growers to diversify their crop portfolios through rotation, intercropping, crop mixtures, etc. These practices not only decrease crop vulnerability, but also reduce farmers' pest (disease, insect, nematode, and weed) pressures and pesticide costs. That helps to ensure food security and food self-sufficiency in the region.

Despite their importance and great potential, the indigenous horticultural crops have not received much attention from researchers. The distribution, cultivation, diseases, insect pests, ingredients, and medicinal mechanism of most indigenous crops have not been well studied. There are few preservation measures for many species as a result of a lack of funding. Some species are facing extinction from pressures brought by human activities, shrinking habitats, diseases/insects, and pollution. Their survival is also threatened by the global warming and related changes in temperatures and precipitation patterns that are beyond their adaptability. There is a pressing need to increase the effort and funding to preserve, collect, maintain, study, and use these precious plant resources. This is particularly critical today because the germplasm may contain genes or traits that can be used to help crop plants combat heat, cold, drought, flooding, and other stresses caused by the climate change.

In the United States, immigrants from Asia are one of the fastest growing sectors of the population. Along with their culture and heritage, new immigrants and ethnic groups also brought their diet habits. Their demands for food products and tastes from homelands have promoted the production of Asian native crops in the United States. This has resulted in a large selection of these items in Oriental food stores throughout the country. The increasing interest in Asian cuisine, especially Chinese, Japanese, Thai, Vietnamese, Korean, and Indian, has led to more demand for new food and crops. These opportunities have drawn more and more producers and retailers into the specialty crop niche market. Although traditional produce showed relatively limited sales growth in recent years, the Asian segment is driving the market's growth, increasing $5 \%$ per year 
from 2006 to 2010. Diverse collections of Asian fruits and vegetables have become an effective marketing strategy to attract and retain loyal customers.

Asia has an enormous population with rising incomes. The globalization of the world economy has opened new markets for U.S. agriculture. In 2008, the total import value of fruits and vegetables was $\$ 30$ billion in Asia. The United States already exports a huge amount of agricultural products to Asia. New Asian crops represent possible export opportunities for the American horticulture industry. However, many of these crops are vulnerable to diseases/pests, have low yields, and need intensive management. More research is needed to study the adaptation of these Asian native crops in the new environments, the development of new cultivars for better yield, quality, and stress tolerance, planting, cultivation, disease/insect/weed control, harvest, post-harvest storage methods, simplification of management or mechanization of production, and nutritional and health benefits.

Although there exist serious challenges, the future of Asia's indigenous horticultural crops is bright. The sustainable and alternative agriculture movements, continued increases in organic production, popularity of farmers' markets and heirloom varieties, the imperative by all countries to protect and conserve their ancestral and indigenous crop resources, and the commercial potential of high-value crops all lead to renewed interest in native horticultural crops around the globe. These crops are also explored and developed today for new markets such as pharmaceutical, cosmetic, industrial, and biofuel uses. The objectives of the workshop were to introduce these interesting horticultural crops from Asia, including their domestication, use, nutritional value, genetic resources, production, and current research status; to discuss the limitations and challenges in their preservation and use; and to identify opportunities, strategies, and priorities for future research and development of these unique and valuable crops in Asia and other parts of the world. 